\title{
Recognizing and preventing epilepsy-related mortality
}

\author{
A call for action \\ OPEN
}

Orrin Devinsky, MD

Tanya Spruill, PhD

David Thurman, MD, $\mathrm{PhD}$

Daniel Friedman, MD, MSc

Correspondence to

Dr. Devinsky:

od4@nyu.edu

\section{ABSTRACT}

Epilepsy is associated with a high rate of premature mortality from direct and indirect effects of seizures, epilepsy, and antiseizure therapies. Sudden unexpected death in epilepsy (SUDEP) is the second leading neurologic cause of total lost potential life-years after stroke, yet SUDEP may account for less than half of all epilepsy-related deaths. Some epilepsy groups are especially vulnerable: individuals from low socioeconomic status groups and those with comorbid psychiatric illness die more often than controls. Despite clear evidence of an important public health problem, efforts to assess and prevent epilepsy-related deaths remain inadequate. We discuss factors contributing to the underestimation of SUDEP and other epilepsy-related causes of death. We suggest the need for a systematic classification of deaths directly due to epilepsy (e.g., SUDEP, drowning), due to acute symptomatic seizures, and indirectly due to epilepsy (e.g., suicide, chronic effects of antiseizure medications). Accurately estimating the frequency of epilepsy-related mortality is essential to support the development and assessment of preventive interventions. We propose that educational interventions and public health campaigns targeting medication adherence, psychiatric comorbidity, and other modifiable risk factors may reduce epilepsy-related mortality. Educational campaigns regarding sudden infant death syndrome and fires, which kill far fewer Americans than epilepsy, have been widely implemented. We have done too little to prevent epilepsy-related deaths. Everyone with epilepsy and everyone who treats people with epilepsy need to know that controlling seizures will save lives. Neurology ${ }^{\circledR}$ 2016;86:779-786

\section{GLOSSARY}

AED = antiepileptic drug; COD = cause of death; PWE = people with epilepsy; SIDS = sudden infant death syndrome; SMR = standardized mortality rate; SUDEP = sudden unexpected death in epilepsy; TCS = tonic-clonic seizures.

Among neurologic disorders in the United States, sudden unexpected death in epilepsy (SUDEP) is the leading cause of lost years of life after stroke. ${ }^{1}$ Because the incidence of epilepsy is greatest among the young, SUDEP, along with status epilepticus, accidents, drownings, and suicide, the most common epilepsy-related causes of death, together lead to substantial premature mortality. Disparities in the burden of epilepsy ${ }^{2}$ mean that epilepsy-related deaths are more frequent among people living in poverty and some minorities. Epilepsy-related mortality remains underappreciated and public health interventions are inadequate. Research is needed to identify ways to reduce the risk. Despite mounting evidence and awareness of the excess mortality faced by people with epilepsy (PWE), we cannot accurately estimate epilepsy-related deaths in the United States nor effectively reduce the death rate. However, evaluating public health or other interventions to prevent epilepsy-related mortality will require accurately quantifying epilepsy deaths in the community and measuring change over time. Compared to other causes with similar public health implications, funding for this problem is deficient by at least an order of magnitude.

Patient, caregiver, medical student, and physician education about SUDEP remains poor. ${ }^{3,4}$ Education is our best opportunity to rapidly reduce the frequency of SUDEP. Further, the

\footnotetext{
From the Departments of Neurology (O.D., D.F.) and Population Health (T.S.), New York University School of Medicine, New York; and the Department of Neurology (D.T.), Emory University School of Medicine, Atlanta, GA.

Go to Neurology.org for full disclosures. Funding information and disclosures deemed relevant by the authors, if any, are provided at the end of the article. The Article Processing Charge was paid by FACES.

This is an open access article distributed under the terms of the Creative Commons Attribution-NonCommercial-NoDerivatives License 4.0 (CC BY-NC-ND), which permits downloading and sharing the work provided it is properly cited. The work cannot be changed in any way or used commercially.
} 
well-deserved focus on SUDEP has unintentionally led to the relative neglect of other epilepsy-related causes of death, which together may exceed those due to SUDEP. ${ }^{5-7}$ Epilepsy also kills people through status epilepticus, drowning, pneumonia, motor vehicle and bicycle accidents, falls, burns, and suicide. Drugs used to treat epilepsy can have rare, fatal allergic reactions and may also kill insidiously by increasing the risk of obesity and cardiovascular disease. ${ }^{8}$ PWE also die from assaults more often than their siblings or the general population. ${ }^{9}$ To prevent epilepsy-related deaths and morbidities (table 1), we must reduce or eliminate seizures.

A collaborative effort is needed to promote awareness and education about epilepsyrelated mortality and to develop, evaluate, and implement effective preventive measures. First, however, we must accurately define epilepsyrelated mortality and assess its frequency. This

Table $1 \quad \begin{aligned} & \text { Selected morbidities of seizures and } \\ & \text { chronic epilepsy }\end{aligned}$
Seizures
Falls and injuries
Head trauma
Soft tissue injuries
Seizure-induced orthopedic disorders
Vertebral compression fractures
Shoulder dislocation
Aspiration pneumonia
Burns
Motor vehicle accidents
Epilepsy
Stigma
Learning disorders and academic problems
Unemployment and underemployment
Osteoporosis (antiepileptic drug-induced)
Progressive cognitive impairment
Memory
Executive function
Attention
Psychiatric illness
Depressive disorder

viewpoint addresses epilepsy-related mortality in the United States.

Advancing the conversation from SUDEP to epilepsyrelated mortality. Lay and academic interest in SUDEP has increased dramatically in the past decade. The attention is justified: SUDEP is the most common cause of epilepsy-related death and individuals with epilepsy have 27-fold higher rates of sudden death than controls. ${ }^{10}$ Recently, the Epilepsy Foundation created the SUDEP Institute, Citizens United for Research in Epilepsy increased SUDEP research funding, Finding A Cure for Epilepsy and Seizures started the North American SUDEP Registry, and NINDS funded a \$25 million multi-institutional Center for SUDEP Research. SUDEP-related articles increased more than 4-fold from 2000-2004 (74) to 2010-2014 (324). Information about SUDEP for patients and caregivers has increased rapidly on Internet sites. ${ }^{10}$

Yet SUDEP, with an annual rate of $\sim 12$ per 10,000 PWE, may account for less than half of all deaths directly caused by seizures (table 2). ${ }^{11-13}$ This conclusion is supported by population-based studies of annual deaths per 10,000 PWE: nearly 5 fatal status epilepticus, ${ }^{14}$ nearly 2 drownings, ${ }^{15} 2-3$ excess suicides, ${ }^{16,17}$ and nearly 6 excess fatal unintentional injuries. ${ }^{7}$ Population-based data often underestimate or misclassify deaths in PWE and fail to represent the general epilepsy population. Among Medicaid patients in Ohio, only $10 \%$ of deaths were considered epilepsy-related. ${ }^{7}$ If status epilepticus and half of the drowning and accidental death cases are considered epilepsy-related, then SUDEP caused only 1 in 25 epilepsy-related deaths. ${ }^{7}$

We need better data. The inability to accurately quantify epilepsy-related deaths is a major obstacle to progress, as are our difficulties comparing results of studies with different methods. One recent study of an open cohort of adult epilepsy patients with Ohio Medicaid insurance yielded a rate of SUDEP of

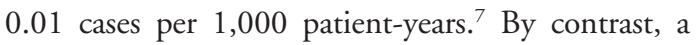
study of long-term mortality in a closed cohort of childhood-onset epilepsy patients in Finland yielded a SUDEP rate of 2.6 cases per 1,000 patient-years. ${ }^{14}$ This is a 250-fold difference; only a small part results from differences in age distributions and socioeconomic status. By far the largest difference in these 2 population-based cohorts stems from different methods of determining cause of death (COD). The Ohio study relied only on information from death certificates, while the Finnish study reviewed clinical records and detailed death investigations in nearly all cases, with autopsies in $70 \%$ of cases that were re-reviewed by experts. ${ }^{12}$ In the low socioeconomic Ohio cohort, the reported SUDEP 


\section{Table 2 Classification of epilepsy-related deaths}

\section{Deaths directly due to epilepsy}

Sudden unexpected death in epilepsy

Status epilepticus

Drowning

Motor vehicle accidents

Falls, burns, and other seizure-related accidents

Deaths due to acute symptomatic seizures ${ }^{59}$

With or without status epilepticus, occurring within 1 week of stroke, traumatic brain injury, anoxic encephalopathy, or intracranial surgery

First identification of subdural hematoma or CNS infection

Active phase of multiple sclerosis or other autoimmune disorders

Deaths indirectly due to epilepsy

Aspiration pneumonia

Suicide

Cardiovascular disease that may be exacerbated or caused by antiseizure drugs

Deaths due to underlying neurologic disease

Brain tumor

Stroke

Metabolic/genetic and neurodegenerative diseases incidence could underestimate the actual rate by more than 100 -fold. ${ }^{7,12}$

In a recent US meta-analysis, SUDEP emerged as the sixth leading neurologic COD but the second leading cause of total years of potential life lost. ${ }^{1}$ Annual lost years of life due to stroke were 189,000 and due to SUDEP were 101,000. This study conservatively estimated SUDEP rate and did not include other epilepsy-related causes of death. Assuming that SUDEP accounts for half of the premature deaths due to epilepsy, epilepsy may be the leading neurologic cause of life years lost.

We should develop a classification system for epilepsy-related mortality (table 2) and partner with medical examiners on guidelines for investigating and reporting death among people with epilepsy. Further, as with SUDEP, criteria to categorize epilepsy-related mortality as possible, probable, or definite, and to modify designations based on whether or not other potential causes of death are present (i.e., plus modifier of SUDEP $\left.{ }^{18}\right)$, are needed.

How do we underestimate epilepsy-related mortality? Many factors contribute to underestimates of SUDEP and other forms of epilepsy-related mortality (table 3). SUDEP is infrequently classified as the COD despite the absence of another credible explanation. A recent personal case (O.D.) exemplifies the problem. A 37-year-old man with generalized convulsions since age 12 years and depression died in his sleep. The medical examiner found mild coronary artery intimal thickening and determined hypertensive cardiovascular disease as the COD. Though the medical examiner was informed that the patient was normotensive and had recent tonicclonic seizures (TCS), neither SUDEP nor epilepsy was listed on the death certificate as a contributing COD. There is a paradox. If a patient with a long-QT gene dies suddenly, the COD is sudden cardiac death. If a patient with epilepsy dies suddenly, the COD is rarely listed as sudden epilepsy death (SUDEP). Cardiovascular disease or arrhythmia is often the assumed COD in an otherwise healthy PWE, ignoring the 27-fold increase of sudden death among PWE. Often, neither seizures nor epilepsy is listed on the death certificate. In Sweden, where autopsy rates are higher than in the United States and medical records are readily accessible, a systematic review of all deaths in 2008 revealed that among 65 SUDEPs, the most common COD on the death certificate was circulatory system disorder; epilepsy was listed as the COD in 23\% and was listed anywhere on the death certificate in only $75 \% .^{19}$

If a PWE dies and there are other potential contributing factors, such as excessive recent alcohol use, the COD may be attributed solely to that factor. Yet, if there is no structural COD (e.g., pancreatitis, gastrointestinal bleed), alcohol withdrawal may trigger SUDEP or status, in which case the proximate and ultimate COD was seizure and epilepsy, respectively; alcohol withdrawal provoked a seizure. There are significantly increased standardized mortality rates (SMRs) of alcohol abuse or dependence among PWE. ${ }^{9,20}$ Similarly, if a seizure causes aspiration pneumonia, and pneumonia is lethal, the COD may be listed as pneumonia, ignoring how epilepsy initiated the causal chain leading to death. The problem is complex since PWE due to static or progressive encephalopathies are prone to aspiration pneumonia, which can result from their primary neurologic disorder, from a seizure, or both. Epilepsy is rarely listed as the ultimate COD although the SMR for pneumonia is elevated over 2.7 to 7.2-fold among PWE. ${ }^{5,20}$ Many individuals with progressive neurometabolic and neurogenetic disorders die after a seizure but only the degenerative disorder is coded on the death certificate. Likewise, if a patient has an acute stroke and dies immediately after a seizure, the COD is typically coded as stroke. If the patient dies several weeks after a stroke or traumatic brain injury but immediately after a seizure, the COD is often listed only as stroke or traumatic brain injury. In one set of instances, epilepsy is the ultimate cause (aspiration pneumonia) and ignored; in the other set, seizures or epilepsy is the proximate cause (degenerative disease, stroke, traumatic brain injury) and ignored. 
Table 3 Factors related to underestimate of epilepsy-related mortality

Underestimate of epilepsy-related mortality

Failure to identify sudden unexpected death in epilepsy (see below)

Failure to ascertain a history of epilepsy

Failure to recognize proximate role of seizure

Neurodegenerative disorders

Stroke

Brain tumor

Following a cranial surgical procedure

Brain infection

Recent alcohol use

Recent illicit drug use

Failure to recognize ultimate role of epilepsy

Aspiration pneumonia

Motor vehicle accident

Bicycle accident

Falls

Drowning

Psychiatric illness (depression, substance abuse, psychosis)

Suicide

Homicide

Obesity secondary to psychiatric medications

Coronary heart disease

Type 2 diabetes

Hypertension

Dyslipidemia

Stroke

Sleep apnea

Burns

Failure to recognize the ultimate role of antiepileptic drugs

Immunological/allergy

Chronic cardiovascular effects (e.g., hypercholesterolemia)

Obesity: see above

Underestimates of sudden unexpected death in epilepsy

Failure to count deaths associated with the following:

Febrile seizures

First seizure

Prolonged seizures (status epilepticus)

Failure to ascertain a history of epilepsy in decedents with sudden death

Misattribution of death

Cardiac, cardiovascular

Cardiopulmonary

Pulmonary

Alcohol-related

Systematic failure to identify sudden unexpected death in epilepsy in the following:

Low socioeconomic groups

The elderly
The underestimation of epilepsy-related mortality is even greater among older adults. The incidence of SUDEP declines markedly after age $50: 8 \%$ of all cases in 51 - to 60 -year-olds, $3 \%$ among 61 - to 70 year-olds, and $<1 \%$ in individuals older than age 70 years. ${ }^{1}$ Among more than 12,000 autopsy cases (2007-2009) in Maryland, 74 were classified as SUDEP; the oldest was 63 years old. ${ }^{21}$ Yet the incidence and prevalence of epilepsy continuously rise after age 65 years. ${ }^{19,22}$ While epilepsy in the elderly is often controlled with antiseizure drugs, ${ }^{22}$ the reported cases drop to almost zero. Are the elderly immune to SUDEP? No. This lack of reported cases reflects that when elderly PWE die suddenly, autopsies are rarely performed, ${ }^{23}$ and when they are, the postmortem examination reveals cardiovascular or pathology in other non-neurologic organs. ${ }^{24}$ The $\mathrm{COD}$ is informed by suggestive pathologic evidence but not the circumstance of death. Notably, in a large community-based study of sudden cardiac arrest, compared to controls, PWE with confirmed ventricular tachycardia/fibrillation had a significantly higher rate of congenital/inherited heart disease and younger age (57 vs 63 years). ${ }^{25}$ Cardiovascular disease rather than epilepsy characteristics were the main determinants of cardiac arrest. ${ }^{25}$

Should we expand our concept of SUDEP? Names and classification systems are critical to communicate but can constrain thought and science. SUDEP requires the diagnosis of epilepsy and excludes status epilepticus. We may be missing mild and severe ends of a spectrum that may provide insights into pathophysiology. Children with febrile seizures who die in bed, prone, during a mild illness are not categorized as SUDEP since a child with febrile seizures does not have epilepsy. ${ }^{26}$ Yet a 2-year-old child with Dravet syndrome due to an SCN1A mutation and fever-induced seizures has epilepsy. A person who dies immediately after a first seizure is not classified as SUDEP since a single seizure is not epilepsy. We exclude cases of status epilepticus ( $>30$ minutes duration) from SUDEP, ${ }^{18}$ yet $\geq 5$ minutes of continuous seizure activity is the current practical definition for status epilepticus. ${ }^{27}$ There mechanisms of death from status epilepticus in the hospital (often iatrogenic) differ from those at home. Instead of viewing prolonged or repetitive seizures (status epilepticus) distinct from SUDEP, a careful study of the temporal pattern of physiologic changes during seizures that range in duration could provide clues to SUDEP mechanisms. Excluding febrile and first afebrile seizures and status epilepticus may honor an arbitrary definition but bury a mountain of data and clues. Seizure duration is a continuous variable. Prolonged seizures may be 
the most informative about SUDEP mechanisms. Excluding them from study will ensure we never find out. Among patients whose SUDEPs were recorded on video EEG, most had 2 or more convulsive seizures during the 24 hours before death, ${ }^{28}$ and several had multiple seizures in sleep without regaining consciousness between seizures. In Dravet syndrome, SUDEP and status epilepticus are the 2 leading causes of death. ${ }^{29}$ Since most SUDEPs occur in sleep and are unwitnessed, how many actually follow status epilepticus? Whether we define status as 5,15 , or 30 minutes, or how much awareness must be regained between seizures is not critical. The border between SUDEP and death due to status is fluid. We should study how seizure intensity, duration, and number interact with an individual's environmental, medical, neurologic, genetic, and epigenetic background to modify risk of death.

Misinformation and lack of education. Are seizures bad for the brain? Traditionally, medicine taught that single seizures are not harmful. Many neurologists tell patients that TCS are only dangerous if they are prolonged or cause physical injuries such as shoulder dislocation, vertebral compression fractures, or burns. My (O.D.) medical and neurologic education in the 1980 s taught me that apart from a seizure while swimming or driving, convulsions are never fatal. For years, I told my patients and students the same thing.

We have not been telling the full story. Seizures are bad for the brain and can be fatal. Gowers ${ }^{30(\mathrm{p} 101)}$ recognized that the interparoxysmal mental state "frequently presents deterioration... defective memory...down to imbecility," most often as "a consequence of epilepsy." In 1904, Spratling ${ }^{31}$ wrote that epilepsy "destroys life suddenly and without warning through a single, brief attack...in from 3 to $4 \%$ of all who suffer from it." A single seizure can injure neurons. ${ }^{32}$ Some people with treatment-resistant epilepsy may have progressive cognitive and behavioral disorders and brain atrophy that correlates with TCS frequency. ${ }^{33}$

Seizures cause most epilepsy-related deaths: drowning, car and bicycle accidents, aspiration pneumonia, alcohol withdrawal, status epilepticus, and SUDEP. Recent or frequent TCS are the most significant risk factors for SUDEP. ${ }^{34}$ When SUDEP is witnessed outside the hospital, the vast majority follow TCS. All 11 SUDEPs and 9 near-SUDEPs (death prevented by resuscitation) recorded on video EEG followed a seizure (TCS 18, complex partial 2). ${ }^{28}$ Class 1 data that seizures cause SUDEP come from a meta-analysis of 11 adjunctive antiepileptic drug (AED) trials. Patients randomized to placebo were
10 times more likely to have SUDEP than those randomized to an AED. ${ }^{35}$ AEDs significantly reduced seizure frequency and SUDEP risk. Excluding SUDEP, high seizure frequency is strongly associated with increased mortality. ${ }^{36}$ Seizures kill.

Information on how recurrent seizures directly cause severe morbidities (table 3) and increase mortality risk is often lacking in current medical, nursing, and patient education. Two UK health care groups recommended that "information on SUDEP should be given to all PWE or their carers to show why preventing seizures is important." 37 The Institute of Medicine ${ }^{38}$ recommended that "PWE and their families need complete and accurate information about the comorbidities and mortality risks." Doctors should be well-informed about SUDEP and educate their patients. We fail our patients, once again. Only a minority of neurologists discuss SUDEP routinely with their patients, ${ }^{3,39}$ although patients and families want information. ${ }^{40}$ Other causes of epilepsy-related mortality also deserve discussion.

Prevention. Can we prevent epilepsy-related mortality? Yes. Preventing seizures, especially TCS, can prevent many deaths due to SUDEP, drowning, status epilepticus, and accidents. Just as effective management of hypertension through lifestyle changes and medication can prevent many strokes, effective management of epilepsy through lifestyle changes, medication, and, when appropriate, dietary or surgical therapy can prevent seizures and reduce morbidity and mortality.

Breakthrough seizures most often result from AED nonadherence. ${ }^{41}$ Unlike other chronic conditions such as hypertension, in which $80 \%$ medication adherence is sufficient for disease control, ${ }^{42}$ optimal seizure control requires near-perfect adherence. PWE have high rates of nonadherence. ${ }^{42}$ Missing a single dose of an AED can be fatal, albeit rarely. Chronic nonadherence increases mortality risk. ${ }^{43}$ Few intervention studies target AED adherence. ${ }^{44}$ The WHO concluded that "Increasing the effectiveness of adherence interventions may have a far greater impact on the health of the population than any improvement in specific medical treatments." ${ }^{44}$ The best AEDs cannot help PWE who do not take them.

Another potentially modifiable risk factor for increased mortality is psychiatric illness. ${ }^{9}$ Among PWE who died from suicide, accident, or assault, $75 \%$ had lifetime history of a psychiatric disorder, vs $41 \%$ for the overall epilepsy cohort. ${ }^{9}$ Epilepsy is often complicated by depression, impulsivity, psychosis, and substance abuse, all increasing risk for suicide, accident, and assault among PWE. ${ }^{9,20,45}$ Up to $30 \%$ of PWE have depression. ${ }^{46}$ Depression diagnosis and treatment are inadequately prioritized in epilepsy 
care, ${ }^{46}$ providing an opportunity to improve patient outcomes. In addition to suicide, ${ }^{47}$ depression can increase mortality through its association with poorer medication adherence. ${ }^{48}$

Is suicide in PWE related to epilepsy? The traditional answer is no. Yet the high incidence and prevalence of psychiatric illness in PWE correlates with duration and severity of epilepsy. Further, suicidality has a bidirectional relationship with epilepsy; suicide rates are increased 3- to 4-fold among epilepsy patients and prior suicide attempt increases the risk for subsequent epilepsy 5-fold, ${ }^{49,50}$ suggesting an underlying shared biology. Screening for suicidality in PWE may identify patients for targeted behavioral and pharmacologic interventions.

There may be other ways to prevent epilepsyrelated mortality. Most SUDEP occurs in sleep when someone is alone and unmonitored, and the decedent is commonly found prone. Sharing a room or a bed or using nocturnal audio-visual monitoring may reduce risk, ${ }^{50-52}$ suggesting that someone nearby to provide basic aid during or following a seizure may be life saving. Devices can alert family members and caregivers that a seizure is occurring ${ }^{53}$ so they may administer rescue medication, roll the person on his or her side, or stimulate the person to improve respiration and arousal after a seizure. ${ }^{53}$

We must inform patients and families about the risk of death and educate them about universal strategies to control seizures, including medication adherence, minimizing provocative lifestyle factors (excess alcohol, sleep deprivation), and considering therapies such as surgery. Patients should be empowered to view one seizure as one too many. Although some patients' seizures cannot be controlled with available therapies, many others settle for incomplete control. Seizure prevention can be discussed in the context of seizure-related accidents since these are less mysterious than SUDEP. The relationship between seizures and accidental death is straightforward.

Health care disparities. Epilepsy is more prevalent in low socioeconomic status groups. ${ }^{54}$ Adults in the Ohio Medicaid program (2002-2006) had a 10-fold higher incidence and prevalence of epilepsy than the general US population. ${ }^{7}$ Socioeconomically deprived PWE, especially young adults, die 17 years prematurely. ${ }^{7}$ By comparison, daily cigarette smoking shortens life by a decade. ${ }^{55}$

Racial/ethnic minority and disadvantaged PWE face health care disparities, ${ }^{56,57}$ and a dearth of research into reducing disparities and improving outcomes. NINDS recently awarded $\$ 40$ million to develop effective, culturally tailored interventions to lower stroke risk among racial/ethnic minorities. ${ }^{58} \mathrm{~A}$ search of NIH Reporter for 2013-2014 for stroke prevention disparities identified 95 grants while epilepsy prevention disparities identified 3 grants. None of the epilepsy grants aimed at improving epilepsy care among low-income or minority populations. Does this shortcoming reflect a lack of interest among epilepsy researchers or funding agencies or both? Why are there such enormous disparities in research between stroke and epilepsy?

Public health. Epilepsy-related mortality should be a public health priority. There are at least 2,750 US cases of SUDEP per year. ${ }^{1}$ In comparison, in 2013, sudden infant death syndrome (SIDS) caused 1,575 deaths, and accidental exposure to smoke, fire, and flames caused 2,760 deaths (Centers for Disease Control and Prevention: www.cdc.gov/nchs/data/nvsr/nvsr64/ nvsr64_02.pdf). Almost every adult American knows that SIDS and fires can kill through public health campaigns. The Back-to-Sleep/Safe-to-Sleep campaigns encouraged basic steps to reduce the risk of SIDS. These campaigns originated from epidemiologic studies on sleep environment and proved successful despite limited understanding of SIDS pathophysiology. Epidemiologic studies of epilepsy identified a definite risk factor for premature mortality: ongoing seizures. We need more evidencebased research on improving health outcomes by reducing seizures through improved medication adherence and healthy lifestyles tailored to different ages, geographies, and cultural groups.

Evaluating the outcomes of the fire and infant safety programs requires reliable ascertainment of fire-related and SIDS deaths before and after the campaigns. We lack public surveillance data for epilepsy-related mortality. Fire safety is taught to every school child and all new mothers are educated on SIDS prevention. Yet epilepsy-related deaths exceed those due to SIDS or fires. We successfully educated more than 250 million Americans about causes of death that annually claim 1,600 to 3,000 lives, but failed to educate 2.9 million Americans about seizure-related deaths that take more than 5,000 lives each year. Why the disparity? Similarly, while lost years of life due to epilepsy may exceed any other neurologic disorder, there is a dearth of research on prevention of epilepsy-related mortality and interventional programs to prevent seizures. Why has so little been done to prevent epilepsyrelated mortality? How can our health care system justify the pitiful investment in prevention? What interventional efforts have we developed to prevent epilepsy-related deaths? What have we done for those who face the greatest risk and receive the poorest care? We have done too little for too long. Far too many have died who could have been saved by information. It is time to act. 


\section{AUTHOR CONTRIBUTIONS}

Dr. Devinsky was involved in the concept design, writing, and editing. Dr. Spruill was involved in the writing and editing. Dr. Thurman was involved in the writing and editing. Dr. Friedman was involved in the concept design, writing, and editing.

\section{STUDY FUNDING}

No targeted funding reported.

\section{DISCLOSURE}

O. Devinsky is supported by NIH (U01 NS090407, U01 NS090415, R01 EB 018308, R01 MH 094480) and CDC (U48 DP 00500801S4). T. Spruill is supported by NIH (R21HL111967, U54NS081765, R01HL117323), CDC (U48 DP 005008-01S4), and Pfizer. D. Thurman is a consultant for UCB Inc. D. Friedman receives salary support for consulting and clinical trial related activities performed on behalf of The Epilepsy Study Consortium, a nonprofit organization. Dr. Friedman receives no personal income for these activities. NYU re ceives a fixed amount from the Epilepsy Study Consortium towards Dr. Friedman's salary. Within the past year, The Epilepsy Study Consortium received payments for research services performed by Dr. Friedman from Alexza Pharmaceuticals, Acorda, Eisai Medical Research, Marinus, Pfizer, SK Life Science, and Upsher Smith. Dr. Friedman has served as a consultant for Cyberonics. He is the editor for SUDEP-related content on epilepsy.com. He receives research support from CDC, NINDS, and Epilepsy Foundation. He has performed medicolegal review surrounding SUDEP. Go to Neurology.org for full disclosures.

Received July 1, 2015. Accepted in final form October 29, 2015.

\section{REFERENCES}

1. Thurman DJ, Hesdorffer DC, French JA. Sudden unexpected death in epilepsy: assessing the public health burden. Epilepsia 2014;55:1479-1485.

2. Burneo JG, Jette N, Theodore W, et al. Disparities in epilepsy: report of a systematic review by the North American Commission of the International League against Epilepsy. Epilepsia 2009;50:2285-2295.

3. Friedman D, Donner EJ, Stephens D, Wright C, Devinsky O. Sudden unexpected death in epilepsy: knowledge and experience among U.S. and Canadian neurologists. Epilepsy Behav 2014;35:13-18.

4. Miller WR, Young N, Friedman D, Buelow JM, Devinsky O. Discussing sudden unexpected death in epilepsy (SUDEP) with patients: practices of health-care providers. Epilepsy Behav 2014;32:38-41.

5. Cockerell OC, Johnson AL, Sander JW, Hart YM, Goodridge DM, Shorvon SD. Mortality from epilepsy: results from a prospective population-based study. Lancet 1994;344:918-921.

6. Forsgren L, Hauser WA, Olafsson E, Sander JW, Sillanpaa M, Tomson T. Mortality of epilepsy in developed countries: a review. Epilepsia 2005;46(suppl 11):18-27.

7. Kaiboriboon K, Schiltz NK, Bakaki PM, Lhatoo SD, Koroukian SM. Premature mortality in poor health and low income adults with epilepsy. Epilepsia 2014;55: 1781-1788.

8. Mintzer S. Metabolic consequences of antiepileptic drugs. Curr Opin Neurol 2010;23:164-169.

9. Fazel S, Wolf A, Langstrom N, Newton CR, Lichtenstein P. Premature mortality in epilepsy and the role of psychiatric comorbidity: a total population study. Lancet 2013;382:1646-1654.

10. Holst AG, Winkel BG, Risgaard B, et al. Epilepsy and risk of death and sudden unexpected death in the young: a nationwide study. Epilepsia 2013;54:1613-1620.
11. Ackers R, Besag FM, Hughes E, Squier W, Murray ML, Wong IC. Mortality rates and causes of death in children with epilepsy prescribed antiepileptic drugs: a retrospective cohort study using the UK General Practice Research Database. Drug Saf 2011;34:403-413.

12. Sillanpaa M, Shinnar S. SUDEP and other causes of mortality in childhood-onset epilepsy. Epilepsy Behav 2013; 28:249-255.

13. Neligan A, Bell GS, Johnson AL, Goodridge DM, Shorvon SD, Sander JW. The long-term risk of premature mortality in people with epilepsy. Brain 2011;134:388-395.

14. Sillanpaa M, Shinnar S. Long-term mortality in childhood-onset epilepsy. N Engl J Med 2010;363: 2522-2529.

15. Bell GS, Gaitatzis A, Bell CL, Johnson AL, Sander JW. Drowning in people with epilepsy: how great is the risk? Neurology 2008;71:578-582.

16. Hauser W, Annergers J, Elveback L. Mortality in patients with epilepsy. Epilepsia 1980;21:399-412.

17. Bell GS, Gaitatzis A, Bell CL, Johnson AL, Sander JW. Suicide in people with epilepsy: how great is the risk? Epilepsia 2009;50:1933-1942.

18. Nashef L, So EL, Ryvlin P, Tomson T. Unifying the definitions of sudden unexpected death in epilepsy. Epilepsia 2012;53:227-233.

19. Faught E, Richman J, Martin R, et al. Incidence and prevalence of epilepsy among older U.S. Medicare beneficiaries. Neurology 2012;78:448-453.

20. Granbichler CA, Oberaigner W, Kuchukhidze G, et al. Cause-specific mortality in adult epilepsy patients from Tyrol, Austria: hospital-based study. J Neurol 2015;262: 126-133.

21. Zhuo L, Zhang Y, Zielke HR, et al. Sudden unexpected death in epilepsy: evaluation of forensic autopsy cases. Forensic Sci Int 2012;223:171-175.

22. Timmons S, Sweeney B, Hyland M, O’Mahony D, Twomey C. New onset seizures in the elderly: aetiology and prognosis. Ir Med J 2002;95:47-49.

23. Ahronheim JC, Bernholc AS, Clark WD. Age trends in autopsy rates: striking decline in late life. JAMA 1983;250: 1182-1186.

24. Gross JS, Neufeld RR, Libow LS, Gerber I, Rodstein M. Autopsy study of the elderly institutionalized patient: review of 234 autopsies. Arch Intern Med 1988;148: 173-176.

25. Lamberts RJ, Blom MT, Wassenaar M, et al. Sudden cardiac arrest in people with epilepsy in the community: circumstances and risk factors. Neurology 2015;85: 212-218.

26. Holm IA, Poduri A, Crandall L, et al. Inheritance of febrile seizures in sudden unexplained death in toddlers. Pediatr Neurol 2012;46:235-239.

27. Lowenstein DH. Status epilepticus: an overview of the clinical problem. Epilepsia 1999;40(suppl 1):S3-S8; discussion S21-S22.

28. Ryvlin P, Nashef L, Lhatoo SD, et al. Incidence and mechanisms of cardiorespiratory arrests in epilepsy monitoring units (MORTEMUS): a retrospective study. Lancet Neurol 2013;12:966-977.

29. Sakauchi M, Oguni H, Kato I, et al. Mortality in Dravet syndrome: search for risk factors in Japanese patients. Epilepsia 2011;52(suppl 2):50-54.

30. Gowers W. Epilepsy and Other Chronic Convulsive Disorders. London: Churchill; 1881. 
31. Spratling WP. Epilepsy and Its Treatment. Philadelphia: WB Saunders; 1904.

32. Rabinowicz AL, Correale J, Boutros RB, Couldwell WT, Henderson CW, DeGiorgio CM. Neuron-specific enolase is increased after single seizures during inpatient video/EEG monitoring. Epilepsia 1996;37:122-125.

33. Thompson PJ, Duncan JS. Cognitive decline in severe intractable epilepsy. Epilepsia 2005;46:1780-1787.

34. Hesdorffer DC, Tomson T, Benn E, et al. Combined analysis of risk factors for SUDEP. Epilepsia 2011;52: 1150-1159.

35. Ryvlin P, Cucherat M, Rheims S. Risk of sudden unexpected death in epilepsy in patients given adjunctive antiepileptic treatment for refractory seizures: a meta-analysis of placebo-controlled randomised trials. Lancet Neurol 2011;10:961-968.

36. Novy J, Belluzzo M, Caboclo LO, et al. The lifelong course of chronic epilepsy: the Chalfont experience. Brain 2013;136:3187-3199.

37. National Institute of Health and Care Excellence. The Diagnosis and Management of the Epilepsies in Adults and Children in Primary and Secondary Care [CG20] 2007. London: National Institute of Health and Care Excellence; 2007.

38. England MJ, Liverman CT, Schultz AM, Strawbridge LM. Epilepsy across the spectrum: promoting health and understanding: a summary of the Institute of Medicine report. Epilepsy Behav 2012;25:266-276.

39. Morton B, Richardson A, Duncan S. Sudden unexpected death in epilepsy (SUDEP): don't ask, don't tell? J Neurol Neurosurg Psychiatry 2006;77:199-202.

40. Kroner BL, Wright C, Friedman D, et al. Characteristics of epilepsy patients and caregivers who either have or have not heard of SUDEP. Epilepsia 2014;55:1486-1494.

41. Montouris GD, Jagoda AS. Management of breakthrough seizures in the emergency department: continuity of patient care. Curr Med Res Opin 2007;23:1583-1592.

42. Dragomir A, Cote R, Roy L, et al. Impact of adherence to antihypertensive agents on clinical outcomes and hospitalization costs. Med Care 2010;48:418-425.

43. Faught E, Duh MS, Weiner JR, Guerin A, Cunnington MC. Nonadherence to antiepileptic drugs and increased mortality: findings from the RANSOM Study. Neurology 2008;71:1572-1578.

44. Al-Aqeel S, Al-Sabhan J. Strategies for improving adherence to antiepileptic drug treatment in patients with epilepsy. Cochrane Database Syst Rev 2011:CD008312.

45. Singhal A, Ross J, Seminog O, Hawton K, Goldacre MJ. Risk of self-harm and suicide in people with specific psychiatric and physical disorders: comparisons between disorders using English national record linkage. J R Soc Med 2014;107:194-204
46. Kanner AM. Depression in epilepsy: prevalence, clinical semiology, pathogenic mechanisms, and treatment. Biol Psychiatry 2003;54:388-398.

47. Jones JE, Hermann BP, Barry JJ, Gilliam FG, Kanner AM, Meador KJ. Rates and risk factors for suicide, suicidal ideation, and suicide attempts in chronic epilepsy. Epilepsy Behav 2003;4(suppl 3):S31-S38.

48. DiMatteo MR, Lepper HS, Croghan TW. Depression is a risk factor for noncompliance with medical treatment: metaanalysis of the effects of anxiety and depression on patient adherence. Arch Intern Med 2000;160:2101-2107.

49. Hesdorffer DC, Hauser WA, Olafsson E, Ludvigsson P, Kjartansson O. Depression and suicide attempt as risk factors for incident unprovoked seizures. Ann Neurol 2006;59:35-41.

50. Hesdorffer DC, Ishihara L, Mynepalli L, Webb DJ, Weil J, Hauser WA. Epilepsy, suicidality, and psychiatric disorders: a bidirectional association. Ann Neurol 2012; 72:184-191.

51. Nashef L, Fish DR, Garner S, Sander JWAS, Shorvon SD. Sudden death in epilepsy: a study of incidence in a young cohort with epilepsy and learning difficulty. Epilepsia 1995;36:1187-1194.

52. Langan Y, Nashef L, Sander JW. Case-control study of SUDEP. Neurology 2005;64:1131-1133.

53. Seyal M, Bateman LM, Li CS. Impact of periictal interventions on respiratory dysfunction, postictal EEG suppression, and postictal immobility. Epilepsia 2013;54: 377-382.

54. Centers for Disease Control and Prevention. Epilepsy in adults and access to care-United States, 2010. MMWR Morb Mortal Wkly Rep 2012;61:909-913.

55. Centers for Disease Control and Prevention. 2014 Surgeon General's Report: the Health Consequences of Smoking: 50 Years of Progress [Online]. Available at: http://www.cdc. gov/tobacco/data_statistics/sgr/50th-anniversary/index.htm. Accessed June 19, 2015.

56. Burneo JG, Black L, Knowlton RC, Faught E, Morawetz R, Kuzniecky RI. Racial disparities in the use of surgical treatment for intractable temporal lobe epilepsy. Neurology 2005;64:50-54.

57. Schiltz NK, Koroukian SM, Singer ME, Love TE, Kaiboriboon K. Disparities in access to specialized epilepsy care. Epilepsy Res 2013;107:172-180.

58. National Institutes of Health. NIH Awards $\$ 40$ Million in Grants to Reduce Stroke Disparities in the U.S. [Online]. Available at: http://www.ninds.nih.gov/news_and_events/ news_articles/pressrelease_40mil_grants_stroke_05012013. htm. Accessed December 8, 2015.

59. Beghi E, Carpio A, Forsgren L, et al. Recommendation for a definition of acute symptomatic seizure. Epilepsia 2010; 51:671-675. 


\section{Neurology}

\section{Recognizing and preventing epilepsy-related mortality: A call for action Orrin Devinsky, Tanya Spruill, David Thurman, et al.}

Neurology 2016;86;779-786 Published Online before print December 16, 2015

DOI 10.1212/WNL.0000000000002253

This information is current as of December 16, 2015

\begin{tabular}{|c|c|}
\hline $\begin{array}{l}\text { Updated Information \& } \\
\text { Services }\end{array}$ & $\begin{array}{l}\text { including high resolution figures, can be found at: } \\
\text { http://n.neurology.org/content/86/8/779.full }\end{array}$ \\
\hline Supplementary Material & $\begin{array}{l}\text { Supplementary material can be found at: } \\
\text { http://n.neurology.org/content/suppl/2016/12/18/WNL.0000000000002 } \\
\text { 253.DC1 }\end{array}$ \\
\hline References & $\begin{array}{l}\text { This article cites } 53 \text { articles, } 6 \text { of which you can access for free at: } \\
\text { http://n.neurology.org/content/86/8/779.full\#ref-list-1 }\end{array}$ \\
\hline Citations & $\begin{array}{l}\text { This article has been cited by } 6 \text { HighWire-hosted articles: } \\
\text { http://n.neurology.org/content/86/8/779.full\#\#otherarticles }\end{array}$ \\
\hline Subspecialty Collections & $\begin{array}{l}\text { This article, along with others on similar topics, appears in the } \\
\text { following collection(s): } \\
\text { All Epilepsy/Seizures } \\
\text { http://n.neurology.org/cgi/collection/all_epilepsy_seizures } \\
\text { Models of care } \\
\text { http://n.neurology.org/cgi/collection/models_of_care } \\
\text { Risk factors in epidemiology } \\
\text { http://n.neurology.org/cgi/collection/risk_factors_in_epidemiology }\end{array}$ \\
\hline Permissions \& Licensing & $\begin{array}{l}\text { Information about reproducing this article in parts (figures,tables) or in } \\
\text { its entirety can be found online at: } \\
\text { http://www.neurology.org/about/about_the_journal\#permissions }\end{array}$ \\
\hline Reprints & $\begin{array}{l}\text { Information about ordering reprints can be found online: } \\
\text { http://n.neurology.org/subscribers/advertise }\end{array}$ \\
\hline
\end{tabular}

Neurology ${ }^{\circledR}$ is the official journal of the American Academy of Neurology. Published continuously since 1951, it is now a weekly with 48 issues per year. Copyright (C 2015 American Academy of Neurology. All rights reserved. Print ISSN: 0028-3878. Online ISSN: 1526-632X.

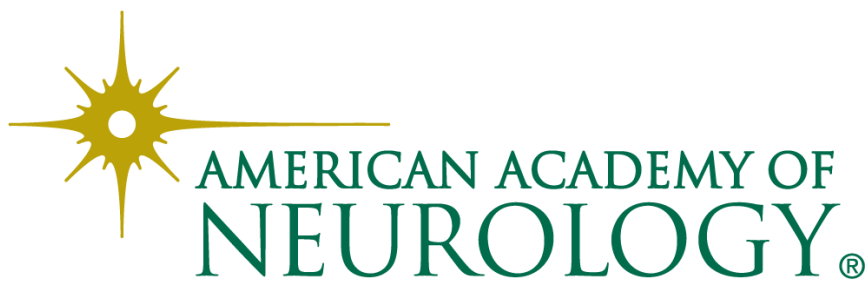

